\title{
GHG Emission as a Measure of Environmental Impacts in Producing Selected Natural Rubber Products
}

\author{
L.W. Kodithuwakku Arachchige ${ }^{1 *}$, N.J.G.J. Bandara ${ }^{2}$, A.G.T. Sugathapala ${ }^{3}$ \\ ${ }^{I}$ Ministry of Industry and Commerce, Sri Lanka \\ ${ }^{2}$ Department of Forestry and Environmental Science, University of Sri Jayawardenapura, Sri Lanka \\ ${ }^{3}$ Department of Mechanical Engineering, University of Moratuwa, Sri Lanka \\ *kallalith@yahoo.com
}

\begin{abstract}
Rubber production has been taking place in Sri Lanka for more than 100 years. This study presents emission of green house gases (GHG) associated with the production of concentrated latex and crepe rubber in Sri Lanka. According to the extent of rubber plantation by districts of Sri Lanka, Kegalle, Kalutara, Ratnapura and Colombo are the major rubber growing districts. Out of these districts Kegalle, Kalutara and Colombo were selected for the study. List of rubber manufacturing industries were used to select industries. Those industries were categorised based on number of workers such as small scale, medium scale and large scale. Industries were selected from all categories proportionate to the total no of industries in the list. Based on the list of rubber factories belonging to plantation companies and three factories belonging to private companies in Sri Lanka were used to collect all activity data were collected for a year. From April 2010 to March 2011 (financial year). The agricultural activities in rubber plantation and fuel consumption for staff transportation were not taken to account.
\end{abstract}

Emission of greenhouse gases associated with the production of primary rubber products (crepe rubber and centrifuge latex) are quantified as functions of activities and emission factors. Diesel uses in fresh latex transportation, electricity use, diesel use for self power generation, production of diesel for latex transportation and self power generation and waste water generation from concentrated and crepe factories were considered for GHG emission calculation. Other than that, ammonia production for concentrated latex factories and firewood use in crepe rubber factories were also considered. Total emission for the year 2010 from the production of concentrated latex is 1,339,663 Ton of $\mathrm{CO}_{2}$ Eq. and from the production of crepe rubber is $8,431,884.1$ ton of $\mathrm{CO}_{2} \mathrm{Eq}$.

The emission factors of the production of concentrated latex and crepe rubber was estimated as 55.016 and 138.123 ton $\mathrm{CO}_{2} \mathrm{Eq}$ per ton of product respectively. Emissions are largely associated with waste water discharges and energy use. This study discusses to reduce GHG emissions from above two product production processes.

Keywords: GHG, Emission, Concentrated latex, Crepe rubber 